\title{
Organizational Development: Driving Forces and Barriers Encountered when Implementing Smoking Cessation Programs
}

\author{
Leslie J. Wardley ${ }^{1}$, Kerri-Anne Mullen ${ }^{2}$, Charles H. Bélanger ${ }^{3} \&$ Robert D. Reid ${ }^{2}$ \\ ${ }^{1}$ Faculty of Applied and Professional Studies, School of Business, Nipissing University, North Bay, Ontario, Canada \\ ${ }^{2}$ Prevention and Rehabilitation Centre, University of Ottawa Heart Institute, Ottawa, Canada \\ ${ }^{3}$ Faculty of Management, School of Commerce, Laurentian University, Sudbury, Canada \\ Correspondence: Charles H. Bélanger, Faculty of Management, School of Commerce, Laurentian University, 935 \\ Ramsey Lake Rd, Sudbury P3E 1C6, Ontario, Canada. E-mail: charles5@magma.ca
}

Received: March 5, 2014

doi:10.5430/ijba.v5n3p19
Accepted: March 19, 2014

Online Published: April 30, 2014

\begin{abstract}
Background: Globally, use of tobacco has been identified as one of the greatest risk factors for mortality and the leading cause of preventable death. The purpose of this paper was to apply the lens of a business change model to the healthcare sector to better understand forces driving the implementation of smoking cessation programs and to identify ways to overcome resistance to changes in smoking behaviour and protocols.

Methods: This paper used a case study approach. Through the interpretation of real-life situations and problems faced by researchers at the University of Ottawa Heart Institute (UOHI), the relationship between society's view towards smoking (drivers of change) and the unique issues encountered when implementing smoking cessation programs (barriers to behavioural change) were explored.

Results: Legislation and health centre regulations have been drivers of change; however, the government-authorized sale of tobacco is still a significant barrier to overcome. At the organizational level, goals and objectives are not clearly defined which resulted in confusion regarding participants' roles, duties and performance standards. At the practitioner level, physicians who demonstrated a lack of confidence in their ability to counsel patients about quitting offer fewer clinical cessation activities. At the patient level, many smokers associate smoking with activities they enjoyed and believed smoking improved their ability to cope with stress, anxiety and/or boredom.

Conclusions: Stronger legislation and making smoking cessation part of the healthcare institution's mission to provide quality care and outreach, can clarify the importance of developing objectives to attain these goals among key stakeholders.
\end{abstract}

Keywords: smoking cessation program, hospital's mission, behavioural change, clinical cessation activities, resistance to change, anti-smoking legislation

Tobacco control is one of the most rational, evidence-based policies in medicine.

(Bettcher, Yach, \& Guindon, 2000)

\section{Background}

Globally, tobacco use imposes a significant growing burden on public healthcare. The World Health Organization has identified global use of tobacco as one of the greatest risk factors for mortality and the leading cause of preventable death (one in ten adult deaths). They project that if current trends continue, over eight million people per year will die from tobacco use by 2030 (Centers for Disease Control and Prevention, 2012; World Health Organization Tobacco Free Initiative, 2012). In Canada, as in other first-world nations, vast improvements have been made over the past several decades in rates of tobacco use due to effective public policies and other tobacco control efforts. However, approximately $17 \%$ of the population continues to smoke and tobacco use remains the leading 
preventable cause of morbidity, disability, death, and cost to Canada's publicly-funded healthcare system (CTUMS, 2012). Given tobacco's link to several diseases, it is no surprise that that prevalence of smoking among hospitalized patients is even higher than that of the general population. The rationale justifying increased efforts to reduce and eventually eliminate the use of tobacco is clear. Despite this, few healthcare organizations address tobacco use as a primary and secondary prevention strategy.

The University of Ottawa Heart Institute (UOHI) has been offering smoking cessation programs in its community since the 1990s. In the early 2000s, UOHI clinicians and researchers developed the Ottawa Model for Smoking Cessation (OMSC), a systematic, practical, clinical approach to identifying and documenting smoking status of patients, initiating evidence-based cessation treatments, and engaging patients in follow up support. The OMSC has to-date been formally implemented in over 140 healthcare sites across eight Canadian provinces using a step-by-step process involving principles of knowledge translation and implementation science. Evaluations of the first nine hospitals to implement the model revealed an $11.1 \%$ absolute increase in long-term cessation rates (from 18.3\% to $29.4 \% ; \mathrm{OR}=1.71 ; 95 \% \mathrm{CI}=1.11,2.64 ; \mathrm{Z}=2.43 ; \mathrm{I} 2=0 \% ; \mathrm{P}=0.02)$. The model systematically identifies, provides treatment and offers follow-up to all smokers seen in clinical practice (Reid, Pipe, Quinlan, \& Oda, 2007). As with many other clinical programs, there have been challenges to the long-term sustainability of the OMSC within some hospitals (Campbell, Mullen, Reece, \& Reid, 2011). With such a logical demand for programs that assist people to stop smoking, one must ask why have there been issues with sustaining smoking cessation programs?

Organizational development (OD) is a field of study that proactively plans change interventions to improve organization effectiveness and the well-being of individuals within the organizations. In practical terms, an organizational development specialist "diagnoses" key priorities, suggests a change-management plan and then guides an organization through the change process (Nielsen, 2012). This plan is developed after several interrelated levels of analysis, which include environmental factors, the overall organization, leaders, individuals, and interlinking processes (Mintzberg, 2011). However, within the healthcare field, there has been little integration of business research into change efforts and the setting of strategic goals (Klarner, Prost, \& Soparnot, 2008), for instance when implementing clinical interventions aimed at dealing with specific behavioural change issues (e.g. smoking cessation).

Healthcare applications are commonly connected to health behaviour change theories such as the Health Belief Model (Rosenstock, Strecher, \& Becker, 1988). One weakness of this theory is that it remains focused on patients' assessments of their self-efficacy rather than presenting a broader viewpoint. From an OD (business) perspective, drivers and barriers of programs are not restricted to patients (Doyle, Claydon, \& Buchanan, 2000; Robertson, Roberts, \& Porras, 1993), as they are in the Health Belief Model. Using an OD perspective, organizations and practitioners are also considered significant players in the implementation of new initiatives, such as the OMSC, and thus need to be considered. Healthcare facilities have strong organizational customs or "the way things are done around here" cultures which can be viewed as advantageous. Routines or approaches to tasks and shared values can increase efficiency. In addition, new members (practitioners and staff) are quickly initiated into processes because managers, policies, and systems reinforce the established culture. However, when attempting to implement a change in routine, these purported strengths can become obstacles to change which can prove hard to amend or overcome, especially when emerging legislation or regulations necessitates a whole new set of organizational goals, policies and processes. Hence, there is a need for a straightforward change model that can be applied by managers and practitioners in practice to increase the chances of a successful change process.

\section{Purpose of the Paper}

The purpose of this paper was to apply the lens of an uncomplicated but effective business change model to the healthcare sector to better understand forces driving the implementation and acceptance of a clinical smoking cessation program and to identify ways to overcome resistance to changes in protocols and smoking behaviour.

\section{Conceptual Model}

\subsection{Three-Step Model of Change}

Lewin's three-step model of change is a matter-of-fact means of conducting an analysis of the change process that is widely used in current change management research (Brown, 2009; Cronshaw \& McCulloch, 2008; Burns, 2004; Zand \& Sorensen, 1975). The premise of the theory is that external and internal pressures can create a need to unfreeze from the status quo, move to a new state and then refreeze the new behaviours to make it permanent. However, a move to the new state requires overcoming barriers that may impede the process. If these barriers are not 
overcome, the changes will not become permanent and people will shift back to previously established behaviours. According to Cronshaw and McCulloch (2008), the original theory by Lewin (1951) was based in concepts fashioned from physics describing vector forces being equal to the change in vector momentum over the change in time. This mathematical basis has been morphed to a more conceptual understanding of force field interpretations.

Simply, to unfreeze and move to acceptance of new behavioural patterns, a force field analysis (Figure 1) must encompass two directions of movement: forces driving change through external and internal pressure to change the current situation and forces restraining it i.e. barriers to change. At the point where there is equilibrium between these two forces there will be a stalemate. Thus, in order for a change in culture to occur the driving forces must exceed the restraining forces (Cronshaw \& McCulloch, 2008; Brophey \& McDermott, 2003; Wagner, Van Reyk, \& Spence, 2001; Zand \& Sorensen, 1975).

Figure 1: The Ottawa Model for Smoking Cessation's fit in the change process I

Level 1- Force field
analysis: Organization
and Practitioner-level
Factors (legislation and
regulations are drivers of
change for organizations
and practitioners; barriers
are resistance to the
implementation of
smoking cessation
protocols.)

Level 2 - Force field analysis: Patient-level Factors (The OMSC now become one of the drivers of change for patients so barriers are the resistance to smoking cessation program supports.)
Level 3 - The

Outcome
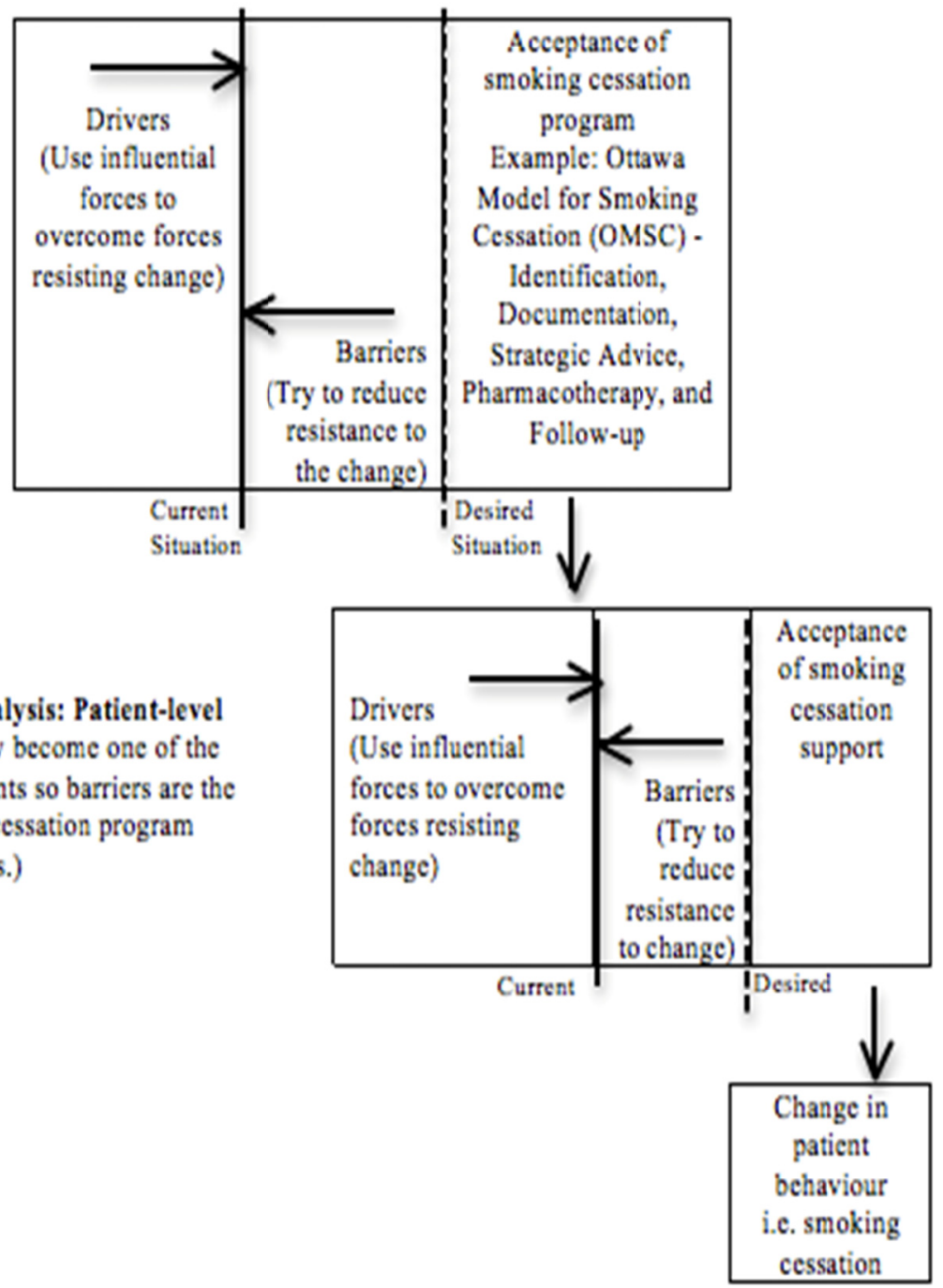

\subsubsection{Level 1 - Force Field Analysis: Organization and Practitioner-level Factors}

Contrary to current practices, a healthcare centre cannot introduce a smoking cessation haphazardly as the desired outcome of amending patient's smoking behaviour requires multiple layers of the three-stage model of change. In 
order to unfreeze the status quo and shift to a new set of behaviours, an analysis of the barriers among organizations and practitioners is important so obstacles are reduced and smoking cessation programs can be successfully implemented in the healthcare setting. Once barriers at this level have been overcome or reduced, the driving force can help support achievement of the desired outcome i.e. implementation of the OMSC. This is where the OMSC fits within the change process. At this point, barriers have been removed and organizations and practitioners have amended their behaviour and included the protocols and supports of the OMSC into their routines, which results in the refreeze stage of the three-stage model.

\subsubsection{Level 2 - Force Field Analysis: Patient-level Factors}

Now that the OMSC has been successfully introduced into the healthcare setting, it now joins social views about smoking (demonstrated through legislation and regulations) as a driving force in changing patient behaviours. Therefore, the area of analysis now becomes the next stages of unfreezing, moving through patients' acceptance of regulations such as not smoking on hospital property and the embracement of OMSC supports.

\subsubsection{Level 3 - The Outcome}

Once drivers are identified and applied and barriers have been reduced or eliminated, the final outcome (i.e. smoking cessation) can be achieved.

\section{Case Method Process}

To isolate barriers to implementation of the OMSC and patient behavioural change, this paper used a case study approach similar to a modified Delphi Technique - collaborative appraising which relies on opinions of experts (Grisham, 2009). Through the interpretation of real-life situations and problems faced by researchers at the UOHI, the relationship between attitudes and beliefs towards smoking and the unique issues encountered when implementing smoking cessation programs and patient acceptance of smoking cessation support were explored. Multiple steps were used in the case method process.

First, a strategy was determined to focus our analysis. The UOHI conducts ample research related to the OMSC and to smoking cessation in clinical settings. While some of the information collected about specific aspects of the OMSC's use has been published, no overall analysis had been conducted to combine the results of the prior studies in an attempt to provide an overarching direction to healthcare sites, which are attempting to initiate a smoking cessation program. This literature conducted by researchers from the UOHI was the initial focus of our case study analysis. We selected cases based on data assessment criteria: we included only those studies that directly identified barriers encountered when attempting to implement smoking cessation programs in health care settings (Level 1 of Figure 1) and those that described patient acceptance of smoking cessation supports (Level 2 of Figure1). The articles selected and a summary of objectives and conclusions are included in Table 1. Recent (i.e. within the past one year) supporting articles from international sources are included in Table 2. Selected cases were examined to find linkages between research data and the sustainability and acceptance of the OMSC. Finally, integration and interpretation of the findings were included in the results and recommendations. 
Table 1. Assessment of UOHI associated authors, their objectives and conclusions

\begin{tabular}{|c|c|c|}
\hline $\begin{array}{l}\text { Author and } \\
\text { Year }\end{array}$ & Objective & Conclusion \\
\hline $\begin{array}{l}\text { Campbell, } \\
\text { Pieters, } \\
\text { Mullen, } \\
\text { Reece, Reid, } \\
2011\end{array}$ & $\begin{array}{l}\text { To determine if there were critical } \\
\text { factors that impacted } \\
\text { sustainability of smoking } \\
\text { cessation programs }\end{array}$ & $\begin{array}{l}\text { Applying a sustainability model to a hospital } \\
\text { smoking cessation program allowed for an } \\
\text { examination of how decisions made during } \\
\text { implementation may impact sustainability. }\end{array}$ \\
\hline $\begin{array}{l}\text { Reid, Mullen, } \\
\text { Pipe, } 2011\end{array}$ & $\begin{array}{l}\text { To present contemporary } \\
\text { information regarding treatments } \\
\text { for smoking cessation in the } \\
\text { cardiac setting. }\end{array}$ & $\begin{array}{l}\text { The identification and documentation of } \\
\text { smoking status of all patients should be a } \\
\text { priority in every cardiovascular setting. }\end{array}$ \\
\hline $\begin{array}{l}\text { Pipe, } \\
\text { Sorensen, } \\
\text { Reid, } 2009\end{array}$ & $\begin{array}{l}\text { To explore association between } \\
\text { physician's smoking status and } \\
\text { beliefs about smoking and } \\
\text { cessation and physician's clinical } \\
\text { interaction with patients }\end{array}$ & $\begin{array}{l}\text { There is a need for specific strategies to } \\
\text { encourage smoking physicians to quit, and to } \\
\text { motivate all practitioners to adopt systematic } \\
\text { approaches to assisting with smoking } \\
\text { cessation. }\end{array}$ \\
\hline $\begin{array}{l}\text { Reid, } \\
\text { Quinlan, } \\
\text { Riley, Pipe, } \\
2007\end{array}$ & $\begin{array}{l}\text { To assess counselling and } \\
\text { pharmacotherapy effectiveness as } \\
\text { treatments for nicotine } \\
\text { dependence }\end{array}$ & $\begin{array}{l}\text { For smokers with coronary heart disease, the } \\
\text { best time to intervene may be during } \\
\text { hospitalization. }\end{array}$ \\
\hline $\begin{array}{l}\text { Reid, Pipe, } \\
\text { Quinlan, Oda, } \\
2007\end{array}$ & $\begin{array}{l}\text { To test previous findings that } \\
\text { despite initial smoking cessation } \\
\text { intervention, almost two-thirds of } \\
\text { smokers resume smoking within } \\
\text { one year of hospitalization for } \\
\text { coronary heart disease }\end{array}$ & $\begin{array}{l}\text { Technology can assist patients when } \\
\text { attempting to quit smoking following } \\
\text { discharge from hospital. }\end{array}$ \\
\hline $\begin{array}{l}\text { Reid, Pipe, } \\
\text { Quinlan, } 2006\end{array}$ & $\begin{array}{l}\text { To describe core elements of a } \\
\text { smoking cessation program and } \\
\text { present data about its reach and } \\
\text { effectiveness. }\end{array}$ & $\begin{array}{l}\text { Hospitalization provides an important } \\
\text { opportunity to intervene with smokers when } \\
\text { their motivation to quit is high. }\end{array}$ \\
\hline $\begin{array}{l}\text { Reid, Pipe, } \\
\text { Higginson, } \\
\text { Johnson, } \\
\text { D'Angelo, } \\
\text { Cooke, et al., } \\
2003\end{array}$ & $\begin{array}{l}\text { To explore stepped-care } \\
\text { interventions as a way reduce the } \\
\text { cost of effective intervention for } \\
\text { smokers which are often } \\
\text { considered to be intensive and } \\
\text { expensive }\end{array}$ & $\begin{array}{l}\text { A stepped-care approach to smoking cessation } \\
\text { after hospitalization increased the short- but } \\
\text { not the long-term smoking abstinence of } \\
\text { patients. }\end{array}$ \\
\hline $\begin{array}{l}\text { D'Angelo, } \\
\text { Reid, Brown, } \\
\text { Pipe, } 2001\end{array}$ & $\begin{array}{l}\text { To evaluate gender differences in } \\
\text { demographic, smoking history, } \\
\text { and perceived stress variable as } \\
\text { predictors of smoking cessation }\end{array}$ & $\begin{array}{l}\text { Predictor variables included: age, education } \\
\text { level, number of years smoking, cigarettes per } \\
\text { day, quit attempts, decisional balance, } \\
\text { processes of change, self-efficacy, and } \\
\text { perceived stress. }\end{array}$ \\
\hline $\begin{array}{l}\text { Reid, Pipe, } \\
\text { Dafoe, } \\
1999\end{array}$ & $\begin{array}{l}\text { To evaluate the incremental } \\
\text { efficacy of telephone counselling } \\
\text { in addition to physician advice in } \\
\text { helping patients to stop smoking }\end{array}$ & $\begin{array}{l}\text { Brief physician assistance, along with nicotine } \\
\text { replacement therapy can help well-motived } \\
\text { smokers to quit. Telephone counselling was } \\
\text { useful in the absence of physician advice or } \\
\text { when self-selected by patients. }\end{array}$ \\
\hline
\end{tabular}


Table 2. Assessment of international authors, their objectives and conclusions

\begin{tabular}{|c|c|c|}
\hline $\begin{array}{l}\text { Author and } \\
\text { Year }\end{array}$ & Objective & Conclusion \\
\hline $\begin{array}{l}\text { Knudsen, } \\
\text { Muilenburg, } \\
\text { Eby, } 2013\end{array}$ & $\begin{array}{l}\text { To examine whether organizations } \\
\text { offering counseling-based smoking } \\
\text { cessation programs sustain them } \\
\text { over time. }\end{array}$ & $\begin{array}{l}\text { Empirical support regarding the importance of } \\
\text { leadership and staff expertise in promoting } \\
\text { sustainment of innovations over time. The } \\
40 \% \text { rate of discontinuation demonstrates } \\
\text { ongoing challenges faced by tobacco control } \\
\text { efforts in substance abuse treatment. }\end{array}$ \\
\hline $\begin{array}{l}\text { Robson, } \\
\text { Bond, } \\
\text { Wolff, } 2013\end{array}$ & $\begin{array}{l}\text { To compare smoking behaviour } \\
\text { characteristics between Caucasian } \\
\text { and Malay smokers using cessation } \\
\text { clinics at the Institute of Psychiatry, } \\
\text { London, United Kingdom and } \\
\text { University Malaya, Kuala Lumpur, } \\
\text { Malaysia. }\end{array}$ & $\begin{array}{l}\text { Caucasians smoked less for social integration } \\
\text { than Malays. Social reasons and the social } \\
\text { environment play a role in smoking uptake, } \\
\text { smoking maintenance and smoking cessation } \\
\text { so the ethnic differences should be kept in } \\
\text { mind when developing and promoting } \\
\text { smoking cessation programs. }\end{array}$ \\
\hline $\begin{array}{l}\text { Proctor, } \\
\text { Myers } \\
\text { Smith, } \\
\text { McRobbie. } \\
\text { Hajek, } 2013\end{array}$ & $\begin{array}{l}\text { To examine the current provision } \\
\text { of support provided to hospitalised } \\
\text { smokers in the United Kingdom. } \\
\text { To determine the barriers and } \\
\text { facilitators to service provision as } \\
\text { well as provider suggestions for } \\
\text { service improvement. }\end{array}$ & $\begin{array}{l}\text { Better performance will rely on guidance } \\
\text { regarding essential practical issues such as } \\
\text { optimal referral pathways, training of health } \\
\text { care professionals, handling of smoking } \\
\text { cessation medications, program referrals } \\
\text { post-hospitalization, and data collection } \\
\text { standardization. }\end{array}$ \\
\hline $\begin{array}{l}\text { Katz et al, } \\
2014\end{array}$ & $\begin{array}{l}\text { To characterize emergency } \\
\text { physicians' and nurses' perceptions } \\
\text { of smoking cessation counseling } \\
\text { and to identify barriers and } \\
\text { facilitators to the implementation of } \\
\text { a multifaceted smoking cessation } \\
\text { intervention. }\end{array}$ & $\begin{array}{l}\text { Workflow, teamwork, and practice policies } \\
\text { that facilitate prescription of smoking } \\
\text { cessation medication, referral for cessation } \\
\text { counseling, and follow-up in primary care all } \\
\text { need to be addressed and systematized in the } \\
\text { emergency department setting. }\end{array}$ \\
\hline $\begin{array}{l}\text { Nour } \\
\text { Eldein, } \\
\text { Mansour, } \\
\text { Mohamed, } \\
2013\end{array}$ & $\begin{array}{l}\text { To assess family physicians' } \\
\text { knowledge, attitude, and practice of } \\
\text { smoking cessation counseling; } \\
\text { aiming to improve quality of } \\
\text { smoking cessation counseling } \\
\text { among family physicians. }\end{array}$ & $\begin{array}{l}\text { Physicians scored lower on passing knowledge } \\
\text { of smoking cessation counseling strategy and } \\
\text { smoking cessation practice. Knowledge and } \\
\text { training were identified as needs in designing } \\
\text { an educational intervention to improve the } \\
\text { quality of smoking cessation counseling } \\
\text { practices. }\end{array}$ \\
\hline $\begin{array}{l}\text { Mahoney et } \\
\text { al, } 2014\end{array}$ & $\begin{array}{l}\text { To examine patient perceptions of } \\
\text { tobacco cessation strategies among } \\
\text { diverse, low socioeconomic, urban } \\
\text { smokers cared for in } \\
\text { community-based primary care } \\
\text { medical offices. }\end{array}$ & $\begin{array}{l}\text { A high percentage of participants reported } \\
\text { owning a cellular phone and nearly } 50 \% \\
\text { reported being receptive to receiving } \\
\text { prerecorded messages about quitting smoking } \\
\text { from a doctor's office. }\end{array}$ \\
\hline $\begin{array}{l}\text { Murray et } \\
\text { al, } 2013\end{array}$ & $\begin{array}{l}\text { To determine if a service designed } \\
\text { to systematically identify and offer } \\
\text { evidence-based support during } \\
\text { smoking cessation to smokers in a } \\
\text { United Kingdom secondary care } \\
\text { setting was effective in increasing } \\
\text { smoking cessation and in } \\
\text { promoting service uptake. }\end{array}$ & $\begin{array}{l}\text { Systematic ascertainment and delivery of } \\
\text { cessation support in secondary care can } \\
\text { significantly enhance smoking cessation } \\
\text { among smokers admitted to hospital. When } \\
\text { evidence based smoking interventions are } \\
\text { delivered by default to all smokers by } \\
\text { specialist staff, service uptake significantly } \\
\text { improved. }\end{array}$ \\
\hline
\end{tabular}




\subsection{Current Implementation of the OMSC in a Healthcare Setting}

The UOHI provides a facilitator who can assist with the implementation of the OMSC. This background support provides assistance with amending policies and training key people to champion the message. However, analysis of what steps should be considered before the UOHI gets involved can increase the sustainability of the smoking cessation program and the ease of its entrance into healthcare centre protocols. The phases used when implementing the OMSC within the hospital setting include: 1) gaining commitment, 2) developing a baseline audit and assessment of procedures, 3) building consensus through training key contacts, revising polices, preparing supports and gathering data, 4) engage in frontline training, 5) delivery of the OMSC program and 6) obtain feedback. These phases are well structured and key to implementing the program. However, many times there is not enough evaluation of the culture of the institution before attempting to implement the phases. How does one progress through the first phase and gain a financial and cognitive commitment from key stakeholders without an understanding of what is driving change and may be impeding commitment?

\subsection{Level 1 - Force Field Analysis: Organizations and Practitioners-level Factors}

\subsubsection{Drivers: Organizational and Practitioner Motivation to Change the Current Situation}

Shifts in societal views about smoking and changes to legislation have brought the issues of smoking-related diseases and deaths to the forefront. Prohibition of smoking in public places has been associated with significant decreases in the occurrence of some critical illnesses (Reid, Quinlan, Riley, \& Pipe, 2007; Ministry of Health and Long-Term Care, 2006). Some hospitals are also starting to take responsibility for their role in assisting people to quit smoking through expanding the smoke-free zone to property-wide and by including smoking cessation programs in their 'best practices' policies (Campbell et al., 2011).

\subsubsection{Restraining Forces: Organizational and Practitioners' Barriers to Change}

Even though hospitals have become drivers of change in smoking behaviours, they are still struggling to remove barriers. As one decision maker (DM) discussed, healthcare settings need to lead by example. In the past, healthcare workers made it acceptable for the public to smoke because they kept silent on the topic of smoking and its negative health-related effects. This behaviour of ignoring the issue did not provide opportunities for smokers to embrace healthier lifestyle choices or obtain support for their addiction (Campbell et al., 2011). This approach has lead to many barriers to change.

\subsection{Organizational-level}

Exploring the study by Campbell et al. (2011), which focused on organizational level sustainability of the OMSC within six hospitals and different program activities, is a good place to start. By surveying key hospital DMs, the researchers identified how choices made during the implementation of the cessation program impacted its sustainability. Factors identified by key informants included: stakeholders' definition of the health problem, the handling of priorities and concerns with the cessation model, and the goodness of fit of the model within the hospital context and resources. In another section,

the authors noted that constraints on financial and staff resources, lack of system supports for the recommended cessation activities, and the need for continued staff support and performance feedback were major barriers to institutionalization (of the OMSC) (Campbell et al., 2011).

When one compares the problems expressed by the stakeholders with those identified by Campbell et al., it becomes obvious that the definition of the health problem among stakeholders was the impediment behind all of these issues. Since there were concerns with how stakeholders defined the health problem (goals and objectives) there were questions about the fit of the model within the context and resources of the hospital. This influenced how the priorities and concerns regarding the cessation model were handled and negatively impacted resource allocation to the program resulting in issues with support for staff and reporting systems.

This lack of consistency regarding how stakeholders define the heath problem was based on a historical confusion about the importance of smoking cessation programs within the healthcare system's culture. Prior generations of smokers were not presented with a clear picture of the dangers of smoking or assistance to quit because it was a topic that was not addressed.

\subsection{Practitioner-level}

Similarly, it is important to understand why practitioners may resist training or incorporating new best practices procedures - even with the support at the organizational level. Research suggests insecurities regarding assigned duties become an issue when implementing smoking cessation programs, as physicians who demonstrate a lack of 
confidence in their ability to counsel patients about quitting offer fewer cessation activities (Pipe, Sorensen, \& Reid, 2009). Hospitals and by extension practitioners have a duty to make their patients as comfortable as possible during their stay. When addicted smokers are admitted to hospitals where they cannot smoke, they experience nicotine withdrawal (Reid, Mullen, \& Pipe, 2011). They risk their own safety when they have to get out of bed and go off the hospital campus to satisfy their need for nicotine. For many years, amending smoking behaviour was not included in the overall goals of hospitals nor directly addressed by healthcare workers' objectives in providing patient care. This omission led to confusion in the healthcare setting about the importance of simple practices such as documenting smoking behaviour on patient charts or the more involved process of providing assistance and support efforts to smokers with whom healthcare professionals came in contract during hospital stays or other interactions.

\subsection{Level 2 - Force Field Analysis: Patients-level Factors}

\subsubsection{Drivers: Patients' Motivation to Change the Current Situation}

Personal health issue caused by smoking is a driver for most hospitalized patients as they identify their own health and the health of others as the most important motivator for wanting to quit. Societal views of smoking have changed as evident by the stronger legislation about smoking in public places and safeguards to those exposed to second-hand smoke. Health centres that have made smoking cessation programs a part of the institution's mission to provide quality care and outreach also become a driving force for smokers' acceptance of smoking cessation support

\subsubsection{Restraining Forces: Patients' Barriers to Change}

Behavioural patterns can influence patients' views of the importance of smoking to their lifestyle. Many smokers not only enjoy the social aspects of being with other smokers or make the association of smoking with activities they enjoy, they also believe smoking improves their ability to cope with stress, anxiety and/or boredom (Reid et al., 2007a). As these beliefs are tied to a smoker's personal identity, and reflect his or her established way to deal with difficult issues, smoking cessation encompasses more than the physical obstacle of nicotine dependence. Quitting becomes a difficult life-altering decision.

Uncertainty regarding one's ability to attain success also became a barrier to behavioural change. Connections have been found between patients' confidence in their ability to quit (self-efficacy) and successful outcomes (Reid, Pipe, Higginson, Johnson, D'Angelo, \& Cooke et al., 2003). According to the literature, there are numerous factors and characteristics which have been associated with behavioural change and better "long-term abstinence following clinician-assisted smoking cessation including high education level, low nicotine dependence, low perceived stress, high proximal self-efficacy, greater social support, and abstinence during the first 1 to 2 weeks of treatment" (D’Angelo, Reid, Brown, \& Pipe, 2001).

So the question now becomes, how do healthcare institutions go about removing or diminishing some of these barriers so the desired changes to healthcare interactions can be implemented and then encourage patients' acceptance of the smoking cessation program?

\section{Sustaining Change through Refreezing}

Focusing on identified resistance to change, we were able to provide a framework of recommendations for amending behaviours within the healthcare setting, which impacts the implementation of smoking cessation programs.

\subsection{Organizational-level}

- Goals and objectives: Contrary to the typical business model where CEO's rewards are tied to stock price or earnings, incentive payouts for administrators in non-profit organizations (NPO) are based on the achievement of missions. One way to improve the commitment of administrators is to use the reduction in smoking among hospitalized patients and their smoking status after discharge as measures of success (Reid, Pipe, \& Quinlan, 2006). These goals are accomplished through a variety of interventions (OMSC) aimed at dealing with specific issues (smoking cessation), as well as through ongoing processes (policies and systems) (Katz et al., 2014; Murray et al., 2013). Making this connection to healthcare's mission to provide quality care and outreach, clarifies the importance of developing objectives to attain these goals among the people who control resource allocations. In addition, it provides a strong incentive for others to embrace the suggested changes as they have management's endorsement.

- Appoint a capable and respected champion: In a number of healthcare locations, designating a smoking cessation nurse counsellor enhanced not only the quality and consistency of intervention offered to smokers; this structure was also cited as an important factor in the long-term sustainability of the model within the hospital (Campbell et al., 2011; Kundsen, Muilenburg, \& Eby, 2013; Reid et al., 2006). 
- Educate, train and prepare people for change: To modify established outlooks, smoking needs to be considered an acute health issue. For smoking cessation programs which attempt to modify behaviour, the inclusion of procedures in healthcare professionals' educational curriculum increases acceptance of the program and reduces attitudes of resistance such as: the perceived futility of intervention and lack of confidence when discussing smoking with patients (Campbell et al., 2011; Nour Eldein, Mansour, \& Mohamed, 2013; Pipe et al., 2009; Proctor, Myers Smith, McRobbie, \& Hajek, 2013). In addition, building awareness regarding potential ethic differences in smoking motivation and behaviour is also important (Robson, Bond \& Wolff, 2013).

\subsection{Practitioner-level}

- Listen to and address apprehensions and obstacles: The previously mentioned research discussed issues relating specifically to physicians' background, which could influence their confidence or views about the importance of smoking cessation. The availability and usage of efficient and effective 'best practices' that allow healthcare professionals to tailor their interactions to fit the particular circumstance are important. If systems and practices (with the related training) were in place at an organizational level it becomes easier for healthcare professionals to incorporate smoking cessation practices into their daily interactions with patients - thus, overcoming their lack of confidence in their ability to impart information and removing the requirement to individually motivate physicians. This systematic approach provides a clear vision of what duties are needed to bring about the change and a vision of the expected successful change in behaviour.

\subsection{Encouraging Patients' Acceptance of Smoking Cessation Program Supports}

Once the smoking cessation program has been successfully implemented the analysis does not abruptly end. Now focusing on patients' identified resistance to change, we were able to provide a framework of recommendations, which impacts patients' acceptance of smoking cessation supports.

- Use assessments and data to encourage change: We know that short physician interactions, along with smoking cessation pharmacotherapy can assist highly motivated smokers to quit (Reid, Pipe, \& Dafoe, 1999). Considering the time since smoking has been deemed an unhealthy pursuit in the mass media and among healthcare professionals, many of the more motivated smokers have decided to quit in recent years. However, for those hard-core smokers it becomes more difficult (Reid et al., 2006). Intervention for smokers needs to include behavioural counselling. Three aspects for smoking cessation that have been effective include skills training on how to quit through developing ways to cope with the side-effects (stress and boredom), intra-treatment social support through encouraging and building smokers' confidence in their ability to quit (Mahoney et al,, 2014) and extra-treatment of social encouragement like community support programs (Pipe et al., 2009).

- Know when to enforce the change with coercive tactics: The final barrier to overcome is the current short-term approach of focusing on smoking cessation programs in place of more long-term solutions. How do we stop people from smoking in upcoming generations when our government, and by extension our society, endorses the sale of tobacco products today? This final barrier is one that is difficult to overcome, as individual and collective rights and freedoms are on a collision course. Tough lines regarding the sale of tobacco may need to be drawn to eventually extinguish the dangers caused by smoking in the future.

\section{Conclusions and Limitations}

In this paper, we have addressed the most common factors found in implementing a smoking cessation program within the hospital setting and identified barriers to patients' acceptance of smoking cessation programs. This paper's focus on drivers and common barriers was an attempt to clarify how healthcare centers can cope with changes demanded by environmental forces such as governments (non-smoking legislation) and external forces (the multiple stakeholders tied to non-profit organizations such as: private donors, foundations, grant funding, government, patients, families, monitoring institutions) while also considering the internal workings of the organization (policies, structures, evaluations and rewards systems). However, the legislated sale of tobacco is still a significant barrier to overcome. Society and its institutions have to sort out what individuals are allowed to do in the name of libertarianism and how far a society can legally protect itself against individual perverse freedoms (The Ottawa Citizen, 2006).

Although the research spanned 16 different national and international peer-reviewed manuscripts, the narrow focus of the literature inclusion criteria does introduce limitations. Extending the case study approach to other programs should be explored in future studies to improve the generalizability of our results. 


\section{References}

Bettcher, D., Yach, D., \& Guindon, E. G. (2000). Global trade and health: key linkages and future challenges. Bulletin of the World Health Organization, 78(5), 521-534.

Brophey, L., \& McDermott, F. (2003). What's driving involuntary treatment in the community? The social, policy, legal and ethical context. Australasian Psychiatry, $11(1), \quad$ S84-S88. http://dx.doi.org/10.1046/j.1038-5282.2003.02020.x

Brown, C. (2009). Technology acceptance and organizational change: An integration of theory. A dissertation submitted to the Graduate Faculty of Auburn University in partial fulfillment of the requirements for the Degree of Doctor of Philosophy Auburn, Alabama.

Burns, B. (2004). Kurt Lewin and the planned approach to change: A re-appraisal. Journal of Management Studies, 41(6), 977-1002. http://dx.doi.org/10.1111/j.1467-6486.2004.00463.x

Campbell, S. P. K., Mullen, K. A., Reece, R., \& Reid, R. D. (2011). Examining sustainability in a hospital setting: Case of smoking cessation. Implementation Science. 2011(6), 108. http://dx.doi.org/10.1186/1748-5908-6-108

Centers for Disease Control and Prevention. Smoking \& Tobacco Use Facts Sheet. (2012, June 7). Retrieved July 2012, from http://www.cdc.gov/tobacco/data_statistics/fact_sheets/fast_facts/

Cronshaw, S., \& McCulloch, A. N. (2008). Reinstating the Lewinian vision: From force field analysis to organization field assessment. Organizational Development Journal, 26(4), 89-103.

CTUMS - The Canadian Tobacco Use Monitoring Survey. (2012). Health Canada, Government of Canada. Retrieved from http://www.hc-sc.gc.ca/hc-ps/tobac-tabac/research-recherche/stat/ctums-esutc_2012-eng.php\#tphp

D'Angelo, M. E., Reid, R. D., Brown, K. S., \& Pipe, A. L. (2001, Nov-Dec.). Gender differences in predictors for long-term smoking cessation following physician advice and nicotine replacement therapy. Canadian Journal of Public Health, 92(6), 418-422.

Doyle, M., Claydon, T., \& Buchanan, D. (2000). Mixed results, lousy process: The management experience of organizational change. British Journal of Management. 11, S59-S80. http://dx.doi.org/10.1111/1467-8551.11.s1.6

Grisham, T. (2009). The Delphi technique: A method for testing complex and multifaceted topics. International Journal of Managing Projects in Business, 2(1), 112-130. http://dx.doi.org/10.1108/17538370910930545

Katz, D., Paez, M.W., Reisinger, H., Gillette, M.T., Vander Weg, M. W., Titler, M.G., ... Ono, S.S. (2014). Implementation of smoking cessation guidelines in the emergency department: a qualitative study of staff perceptions. Addiction Science \& Clinical Practice, 9(1). Retrieved from http://www.ascpjournal.org/content/9/1/1

Klarner, P., Prost, G., \& Soparnot, R. (2008). Organizational change capacity in public services: The case of the World Health Organization. Journal of Change Management, 8(1), 57-72. http://dx.doi.org/10.1080/14697010801937523

Knudsen, H. K., Muilenburg, J., \& Eby, L.T. (2013). Sustainment of smoking cessation programs in substance use Disorder treatment organizations. Nicotine Tob Res., 15(6), 1060-1068. http://dx.doi.org/10.1093/ntr/nts242

Lewin, K. (1951). Field theory in social science. New York, NY: Harper and Row.

Mahoney, M.C., Erwin, D.O., Widman, C., Masucci Twarozek, A., Saad-Harfouche, F.G., Underwood III, W., \& Fox, C.H. (2014). Formative evaluation of a practice-based smoking cessation program for diverse populations. Health Education \& Behavior, 41(186). http://dx.doi.org/10.1177/1090198113504415

Ministry of Health and Long-Term Care. Smoke-Free Ontario Act - Protecting Ontarians. (2006). Retrieved July 2012, from http://www.mhp.gov.on.ca/en/smoke-free/legislation/in-brief.asp

Mintzberg, H. (2011). From management development to organization development with Impact. OD Practitioner, 43(3), 25-29.

Murray, R.L., Leonardi-Bee, J., Marsh, J., Jayes, L., Li, J., Parrott, S., \& Britton, J. (2013). Systematic identification and treatment of smokers by hospital based cessation practitioners in a secondary care setting: cluster randomised controlled trial. BMJ 2013(347), f4004. http://dx.doi.org/10.1136/bmj.f4004 
Nielsen, L. (2012). Quantifying qualitative OD results: Dispelling the touchy-feely stigma. OD Practitioner, 44(1), $38-43$.

Nour Eldein, H., Mansour, N.M., \& Mohamed, S.F. (2013). Knowledge, Attitude and Practice of Family Physicians Regarding Smoking Cessation Counseling in Family Practice Centers, Suez Canal University, Egypt. Journal of Family Medicine and Primary Care, 2(2). http://dx.doi.org/10.4103/2249-4863.117411

Pipe, A. L., Sorensen, M., \& Reid. R. D. (2009, Jan.). Physician smoking status, attitudes toward smoking, and cessation advice to patients: An international survey. Patient Education and Counseling, 74(1), 118-123. http://dx.doi.org/10.1016/j.pec.2008.07.042

Proctor, B., Myers Smith, K., McRobbie, H., \& Hajek, P. (2013). National Survey of Stop Smoking Service Provision in Hospitals in Great Britain: Current Practice, Barriers and Facilitators. Journal of Addiction Research \& Therapy, 4(4).

Reid, R. D., Mullen, K. A., \& Pipe, A. L. (2011). Systematic approaches to smoking cessation in the cardiac setting. Current Opinions in Cardiology, 26, 443-448. http://dx.doi.org/10.1097/HCO.0b013e3283497499

Reid, R. D., Pipe, A. L., Quinlan, B., \& Oda, J. (2007b, June). Interactive voice response telephony to promote smoking cessation in patients with heart disease: A pilot study. Patient Education and Counseling, 66(3), 319-326.

Reid, R. D., Pipe, A., \& Dafoe, W. A. (1999, June). Is telephone counselling a useful addition to physician advice and nicotine replacement therapy in helping patients to stop smoking? A randomized controlled trial. Canadian Medical Association Journal, 160(11), 1577-1581.

Reid, R. D., Quinlan, B., Riley, D. L., \& Pipe, A. L. (2007a, July). Smoking cessation: Lessons learned from clinical trial evidence. Current Opinions in Cardiology, 22(4), 280-285.

Reid, R., Pipe, A. L., Higginson, L., Johnson, K., D'Angelo, M. S., \& Cooke, D. et al. (2003, May-June). Stepped care approach to smoking cessation in patients hospitalized for coronary artery disease. Journal of Cardiopulmonary Rehabilitation, 23(3), 176-182. http://dx.doi.org/10.1097/00008483-200305000-00003

Reid, R.D., Pipe, A. L., \& Quinlan, B. (2006, July). Promoting smoking cessation during hospitalization for coronary artery disease. Canadian Journal of Cardiology, 22(9), 775-780. http://dx.doi.org/10.1016/S0828-282X(06)70294-X

Robson, N., Bond, A., \& Wolff, K. (2013). A comparison of smoking behaviour characteristics between Caucasian smokers in the United Kingdom and Malay smokers in Malaysia. Preventive Medicine, 57, Supplement( 0$)$, S8-S10. http://dx.doi.org/10.1016/j.ypmed.2013.04.010

Robertson, P., Roberts, D., \& Porras, J. (1993). Dynamics of planned organizational change: Assessing empirical support for a theoretical model. Academy of Management Journal, 36(3), 619- 634. http://dx.doi.org/10.2307/256595

Rosenstock, I. M., Strecher, V. J., \& Becker, M. H. (1988). Social learning theory and the health belief model. Health Education Quarterly, 15, 175-183. http://dx.doi.org/10.1177/109019818801500203

The Ottawa Citizen (2006). Smoking ban puts Royal Ottawa in awkward spot. [cited February 4, 2006].

Wagner, R., Van Reyk, P., \& Spence, N. (2001). Improving the working environment for workers in children's welfare agencies. Child \& Family Social Work, 6(2), 161- 178. http://dx.doi.org/10.1046/j.1365-2206.2001.00199.x

Wee, L. H., Shahab, L., Bulgiba, A., \& West, R. (2011). Stop smoking clinics in Malaysia: Characteristics of attendees and predictors of success. Addictive Behaviors, 36(4), 400-403. http://dx.doi.org/10.1016/j.addbeh.2010.11.011

World Health Organization Tobacco Free Initiative (TFI) (2012). Why tobacco is a public health priority. [cited July, 2012 ]. http://www.who.int/tobacco/health_priority/en/

Zand, D. E., \& Sorensen, R. E. (1975). Theory of change and the effective use of management science. Administrative Science Quarterly, 20(4), 532-545. http://dx.doi.org/10.2307/2392021 